\title{
PBX 9502 CORNER TURNING \\ Test Fire and Data Analysis
}

Rex Avara

QUALITY DIVISION

FEBRUARY 1979

Process Development 


\section{NOTICE}

This report was prepared as an account of work sponsored by the United States Government. Neither the United States nor the United States Department of Energy, nor their employees, nor any of their contractors, subcontractors, or their employees, makes any warrany, express or implied, or assumes any legal liability or responsibility for the accuracy, completeness or usefulness of any information, apparatus, product or process disclosed, or represents that its use would not infringe privately-owned rights.

Printed in the United States of America

National Technical Information Service

U.S. Department of Commerce

5285 Port Royal Road

Springfield, VA 22161

Price: Printed Copy $\$ 4.00$; Microfiche $\$ 3.00$ 


\section{DISCLAIMER}

This report was prepared as an account of work sponsored by an agency of the United States Government. Neither the United States Government nor any agency Thereof, nor any of their employees, makes any warranty, express or implied, or assumes any legal liability or responsibility for the accuracy, completeness, or usefulness of any information, apparatus, product, or process disclosed, or represents that its use would not infringe privately owned rights. Reference herein to any specific commercial product, process, or service by trade name, trademark, manufacturer, or otherwise does not necessarily constitute or imply its endorsement, recommendation, or favoring by the United States Government or any agency thereof. The views and opinions of authors expressed herein do not necessarily state or reflect those of the United States Government or any agency thereof. 


\section{DISCLAIMER}

Portions of this document may be illegible in electronic image products. Images are produced from the best available original document. 


\title{
PBX 950己 CORNER TURNING TEST FIRE AND DATA ANALYSIS
}

\author{
Rex Avara \\ QUALITY DIVISION \\ (February 1979) \\ Process Development
}

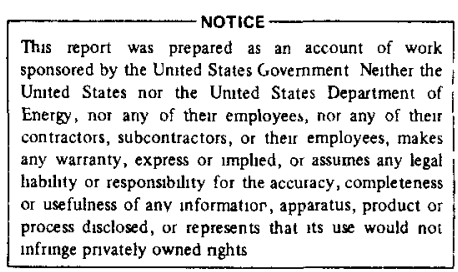

\section{ABSTRACT}

This report describes the test fire and data analysis of one technique to be utilized in lot characterization of PBX 9502. The corner turning distance is expected to vary $\pm 2.1 \mathrm{~mm}$ on lot-to-lot variation, primarily due to density variations in the PBX 9502. The uncertainty of these measurements is estimated to be $\pm 0.2 \mathrm{~mm}$ as determined from errors of the systems and techniques employed in the tests.

\section{INTRODUCTION}

The corner turning test measures the detonation breakout position, along the cylindrical surface, of an end detonated piece of PBX 9502. The test charge piece, $50 \mathrm{~mm}$ diameter $\mathrm{x}$ $50 \mathrm{~mm}$ long, is initiated at the central area of one end by two PBX 9502 booster charges (18 mm diameter $x 50 \mathrm{~mm}$ long). The high explosive assembly is shown in Fig. 1. An SE 1 detonator and two pellets (PBX 9407 and PBX 9404) act as a standard donor to initiate the PBX 9502 booster charges. The two booster charges provide adequate "run-up" length for reproducible conditions prior to test charge initiation.

A detonation breakout position is determined by observing the first emergence of light on a $50 \mathrm{~mm}$ diameter test charge cylindrical surface. Light emission is accomplished by shocking a thin layer of trapped air on the test charge surface, i.e., air being contained within a $0.025 \mathrm{~mm}$ thick cigarette paper (flasher) which is covered by transparent Mylar tape.

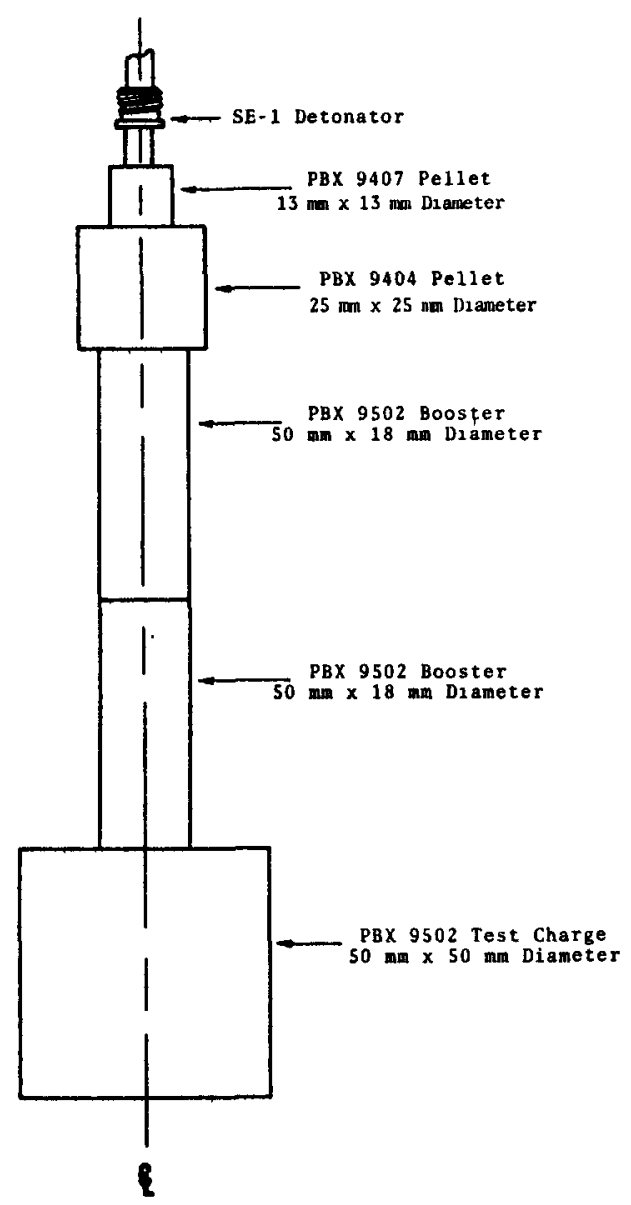

Fig. 1. Corner Turning Explosive Assembly 
The Mylar tape temporarily quenches light immediately after a shock wave transits the flasher.

Streak photography is employed to record the first emission of light by observing a narrow slit portion of the test charge flasher (slit aligned parallel to pellet axis) while the test charge image moves normal to its axis. The results are recorded on film for precise measurement of the first light relative to a small "blanked" area (fiducial) on the flasher paper. A $0.254 \mathrm{~mm}$ diameter copper wire, aligned normal to the slit viewing area, covers the flasher and provides a fiducial blank. This wire is aligned at a pre-determined position for reference measurement to the test charge/booster junction (or corner). Two wires are used in case of partial streak record loss.

\section{TEST FIRE ASSEMBLY}

The explosive components are bonded together with Eastman 910 while slightly compressed to achieve minimum glue gaps at the junction surfaces. Glue fixtures are utilized to assure mutual alignment of matching component axes within $0.08 \mathrm{~mm}$. This includes allowed tolerances of $\pm 0.05 \mathrm{~mm}$ diameter for machining the explosive components. Refer to Fig. 2 for bonding sequence. The flasher is prepared and attached prior to detonator assembly.

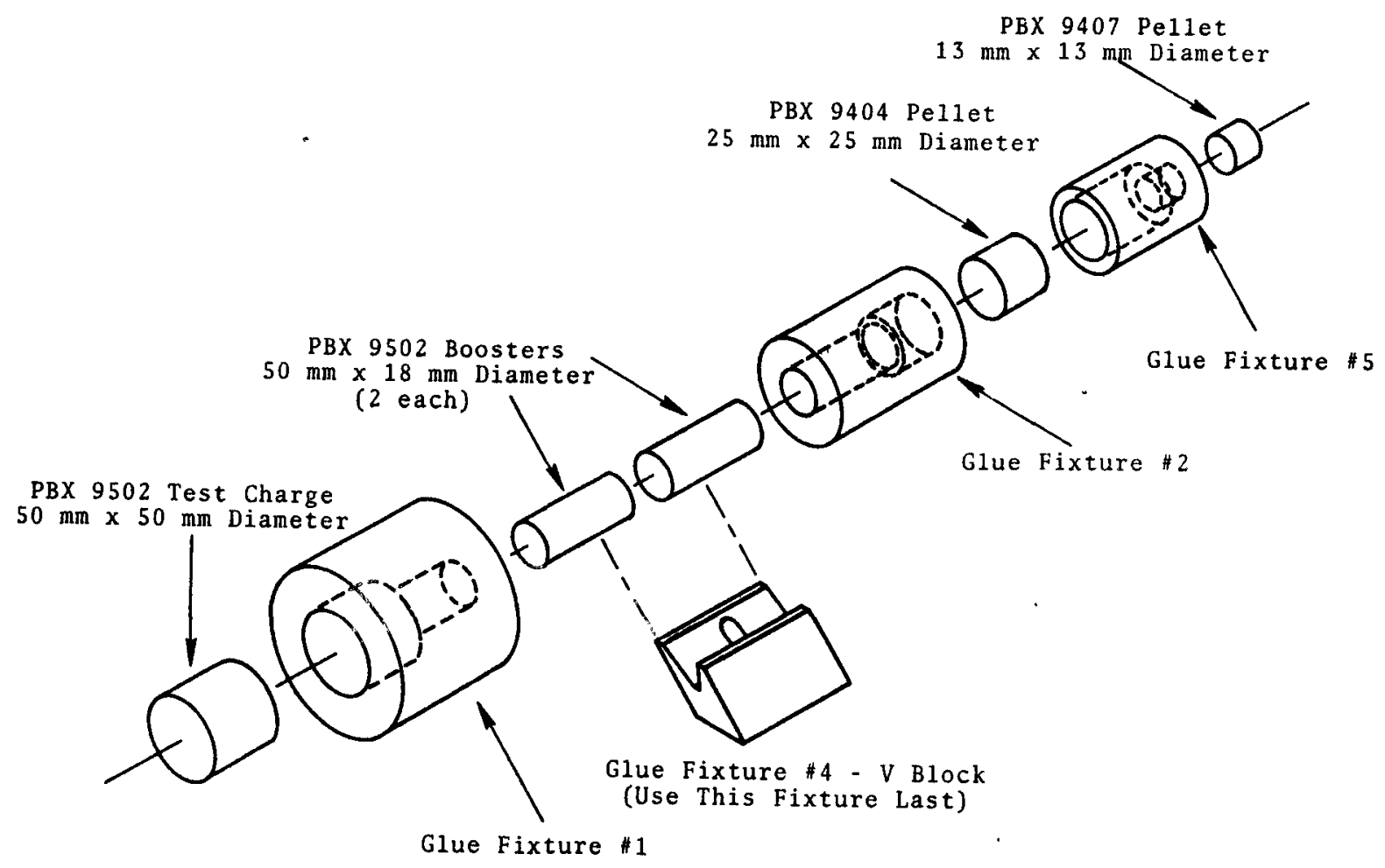

Fig. 2. Bonding of Explosive Components 
Fig. 3 shows preparations for the flasher gap and fiducial wires. A cigarette paper is cut and placed on a clean smooth surface, i.e., glass, and covered with a strip of clear Mylar tape, then tamped with a smooth instrument. The flasher assembly is then transferred to the side of a test charge and taped tightly. A split marking fixture (glue fixture No. 3) provides reference edges for marking fiducial wire locations and center lines on the test charge.
Two fiducial wires are attached across the flasher at the marked positions $(10 \mathrm{~mm}$ and $20 \mathrm{~mm})$. Black tape is used to reduce side flash during streak photography. Refer to Fig. 4 for the completed assembly. A precision metric scale is attached for determining the image magnification on a streak record film. Finally, a det adapter is bonded to the PBX 9404 pellet and the shorted detonator is installed and locked with an SE 1 lock nut. Note that the det adapter fits to the PBX 9407 pellet to assure detonator concentricity.

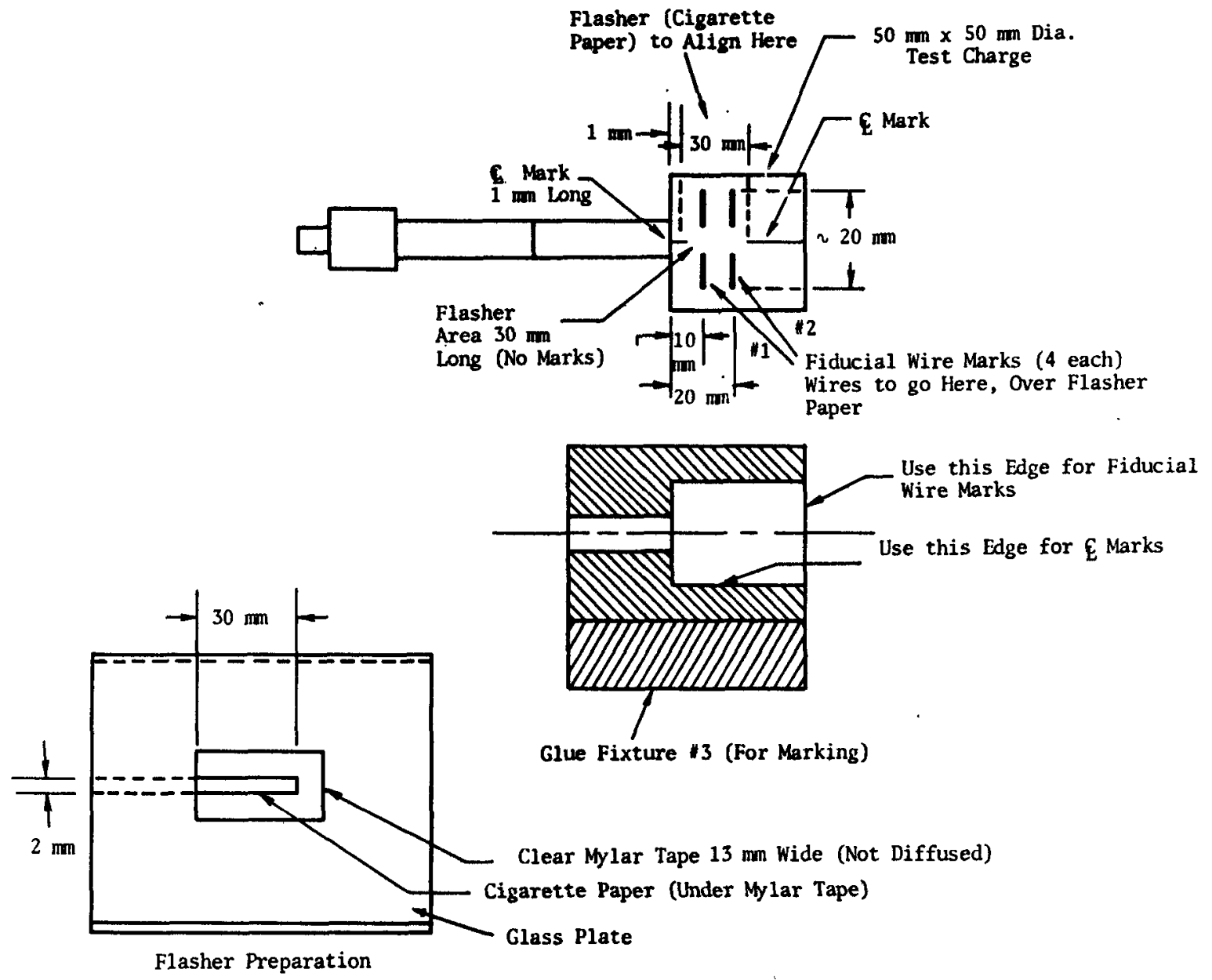

Fig. 3. Fiducial Wire and Flasher Gap Preparation 


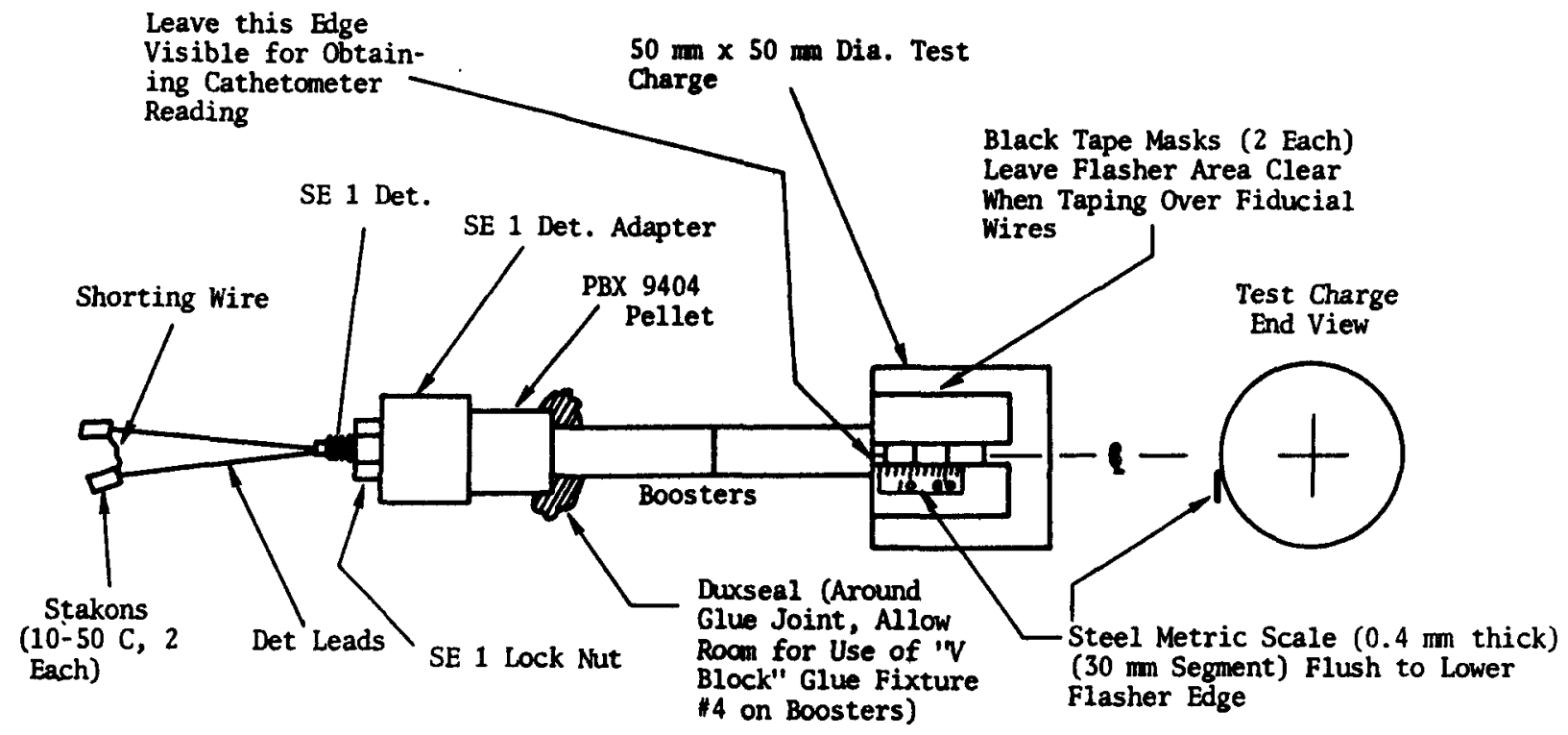

Fig. 4. Completed Explosive Assembly

The completed assembly is then measured for fiducial wire positions using a Gaertner M912 cathetometer. The cathetometer allows accurate measurements $( \pm 0.05 \mathrm{~mm}$ maximum) of the wire locations referenced to the test charge/booster junction (corner). Duxseal is then applied at the booster/ PBX 9404 junction to retard flash and detonation products during streak photography.

The assembly is installed in an environmental box for temperature control during test fire (see Fig. 5). The support blocks are located, using $\mathrm{V}$ blocks at the boosters, to assure the test charge center line is parallel to the plate glass viewing window. The test piece is then rotated for proper center line height of the flasher, and bonded to the support blocks. A thermocouple is bonded to the $50 \mathrm{~mm}$ test charge cylindrical surface (opposite the flasher side) with Devcon 5 minute epoxy, then covered with a small amount of Duxseal for thermal protection from ambient air. This wire is run out of the box with the det leads. Air and test piece temperatures are monitored during test fire operations for controlling a test piece temperature to match conditions recorded with the cathetometer measurements. 

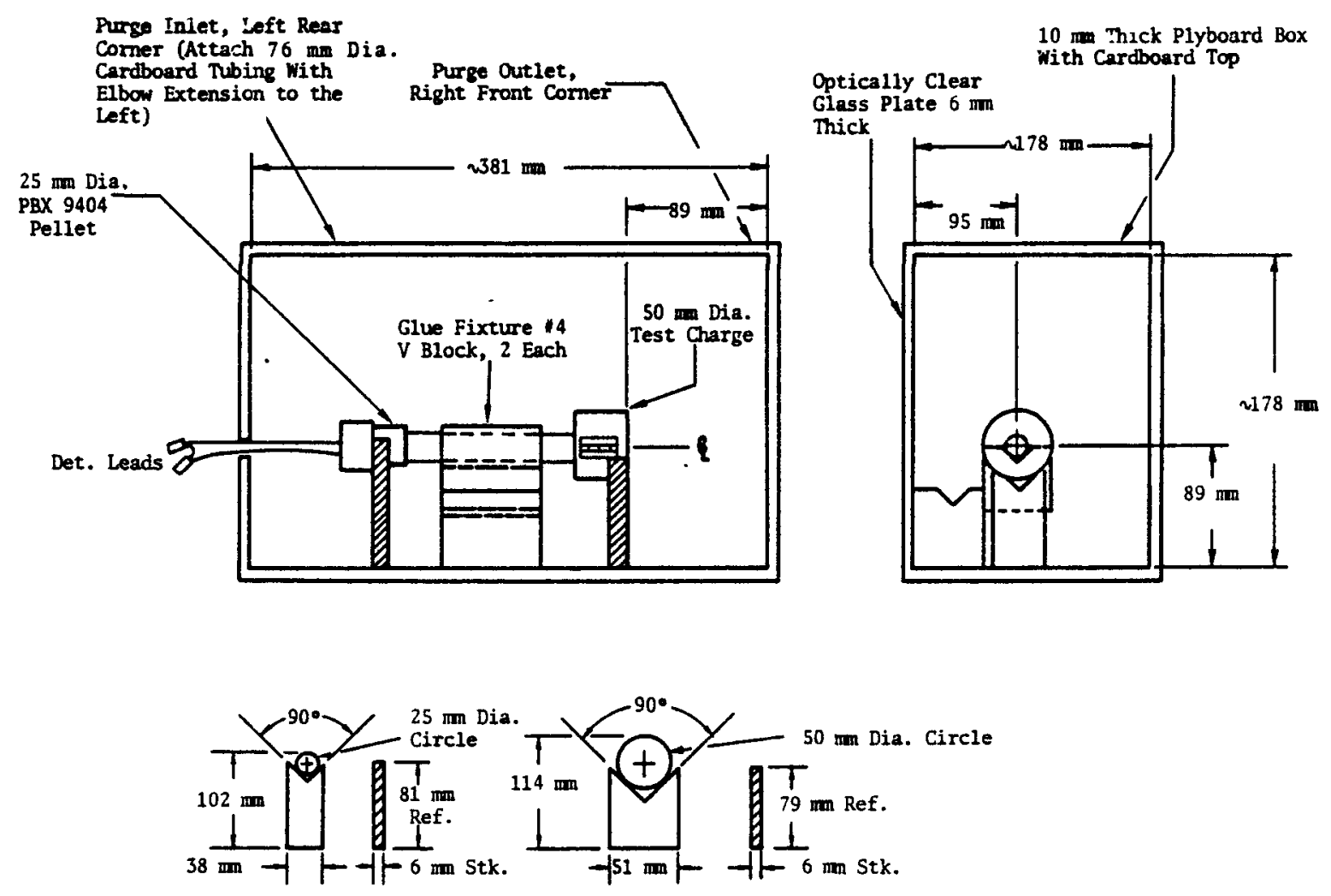

Support Blocks (Material Wood)

Fig. 5. Test Fire Assembly Environmental Box

\section{TEST FIRE OPERATIONS}

A setup box (Fig. 6) is used prior to test fire to minimize temperature control difficulties. This box simulates a TF assembly in the streak camera optics shown in Fig. 7. A 1 $\mathrm{mW} \mathrm{He}-\mathrm{Ne}$ laser, inserted into the optical train, provides visual alignment of the setup box, or test part. The box is moved for correct position of the focused laser spot, then tilted for angular alignment by observing the beam reflected from the plate glass window. The streak camera external optics image the test piece, or setup chart, at the slit plate. This image, which is masked by the slit, is reimaged onto the film plane by the camera internal optics (see Fig. 8). A static photograph of the setup resolution chart is obtained to verify magni- fication of $1.00 \pm 0.05$ and acceptable image quality. A perimeter line drawn around the setup box aids in initial alignment of a test fire environmental box to the table top.

Prior to test firing, the environmental box is purged with air which is temperature controlled to match conditions (21 C nominal) during the explosive assembly and cathetometer measurements. Previous environmental tests indicate that when the box is purged as described above, the temperature inside the explosive changes approximately $0.1 \mathrm{C}$ per minute with a 7 to 10 minute time lag when referenced to a covered thermocouple on the outer surface. Consequently, the desired temperature is maintained for at least 15 minutes prior to test firing. Allowed temperature variation is $\pm 1 \mathrm{C}$. 


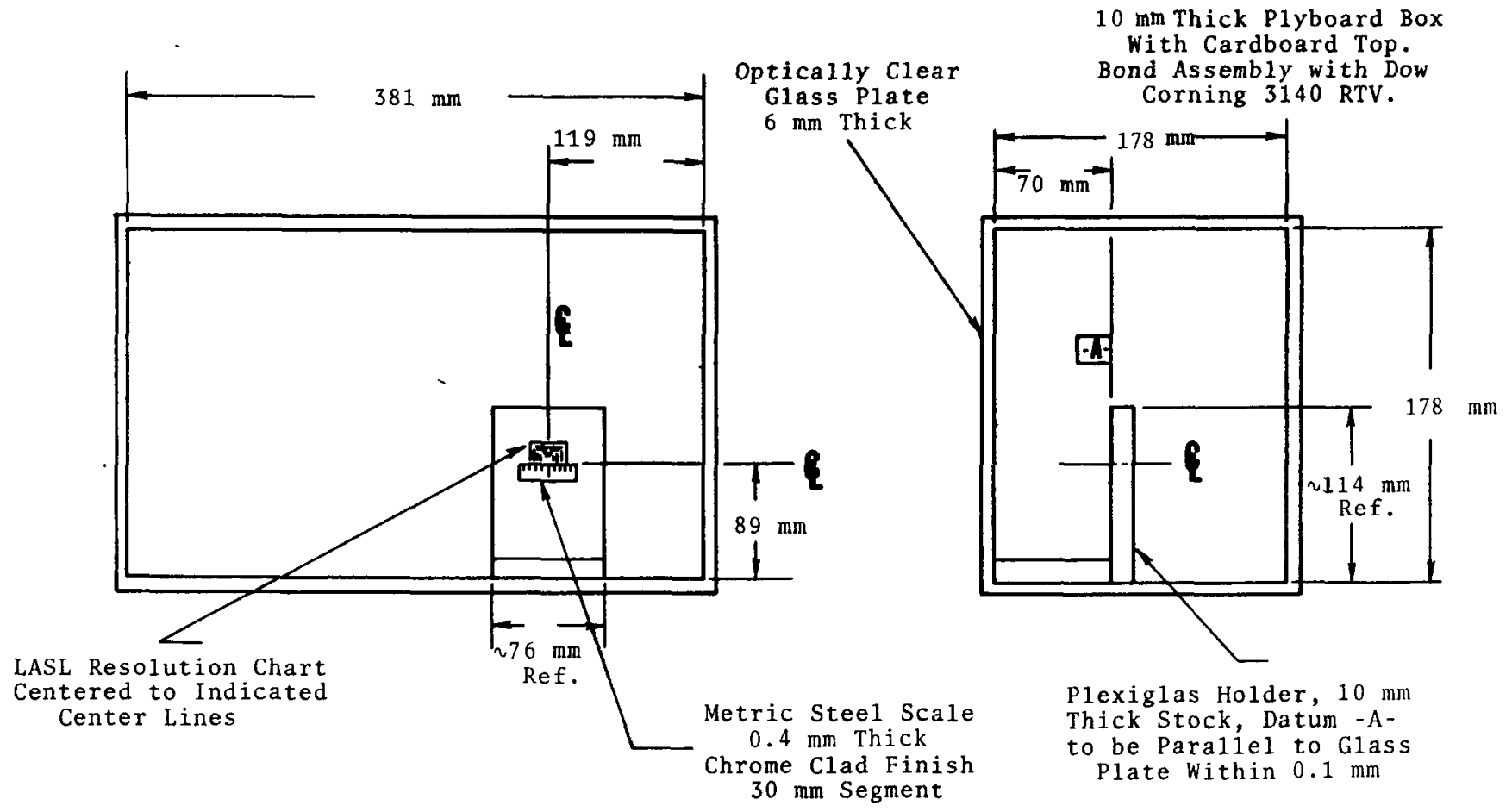

Fig. 6. Test Fire Setup Box

CORNER TURNING TF OPTICS SETUP
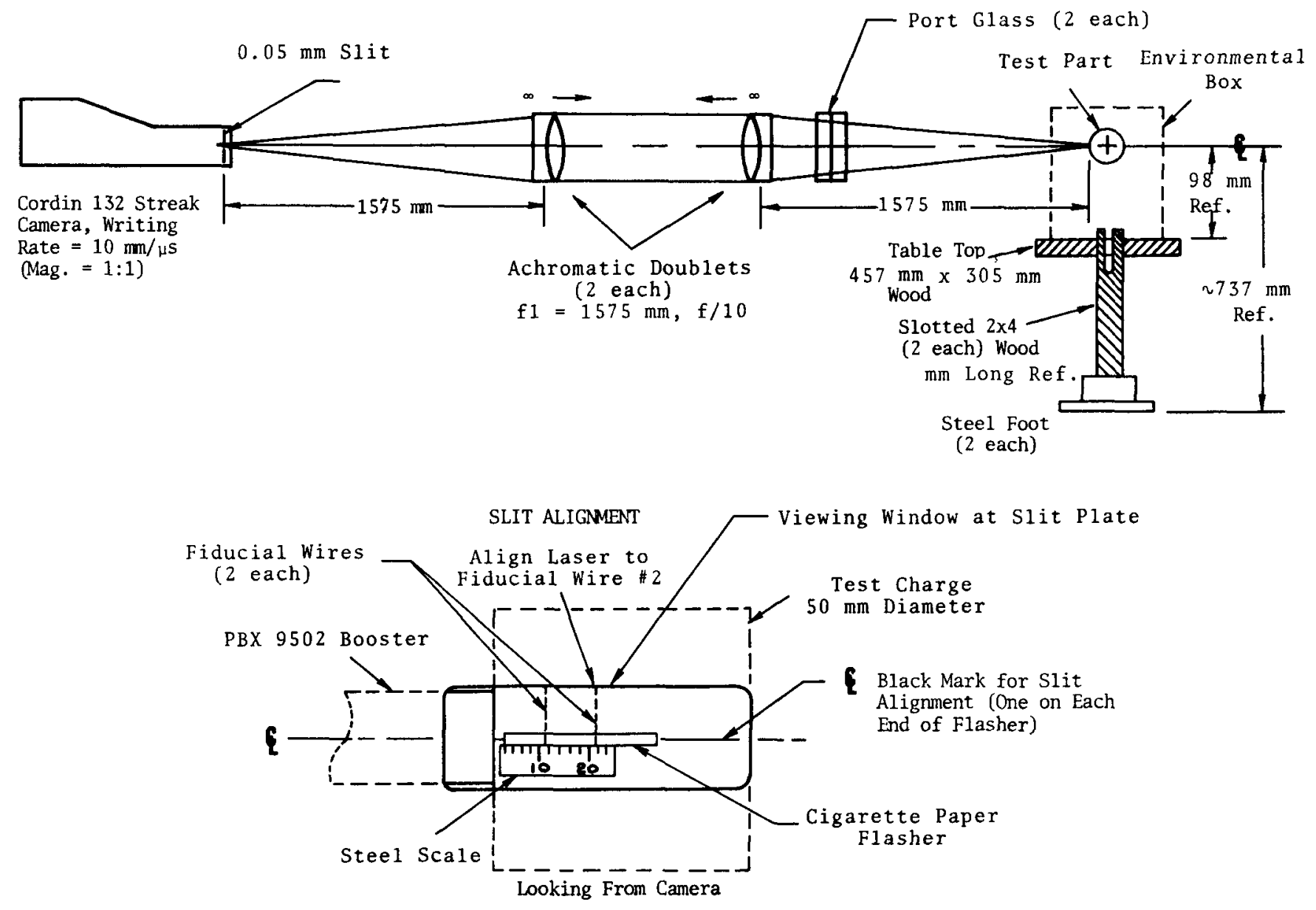

Fig. 7. Streak Camera External Optics 


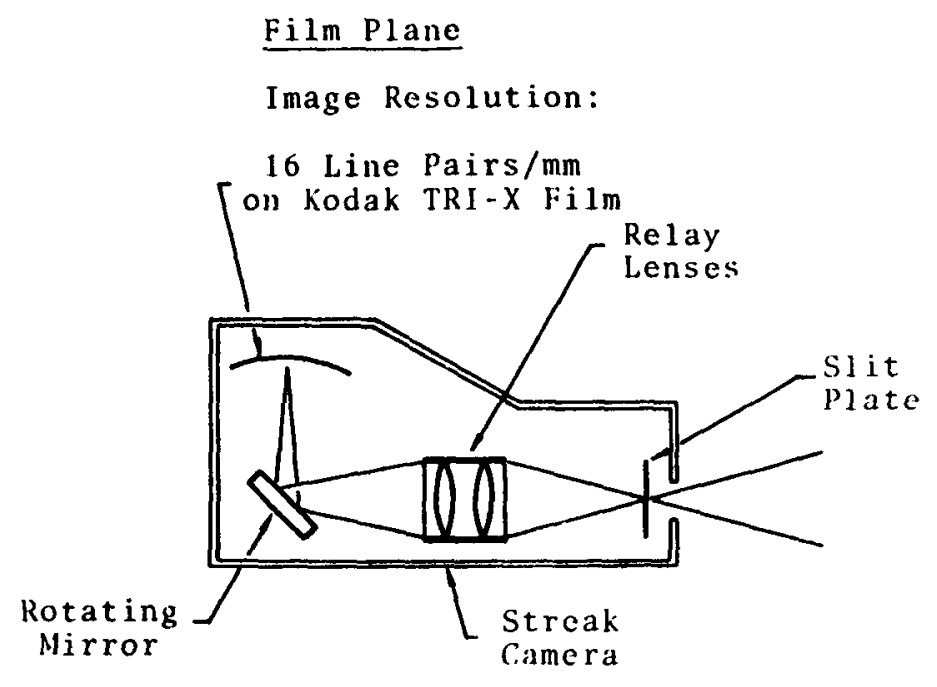

Fig. 8. Streak Camera Internal Optics
During test firing, the streak camera rotating mirror sweeps an image along the film plane at a nominal writing rate (image velocity) of $10 \mathrm{~mm} / \mu \mathrm{s}$. A test fire is time synchronized to the streak camera by reference to a generated electronic signal taken from the rotating mirror via reflected infrared lights. A capacitor charged to $2.5 \mathrm{KV}$ discharges only when proper mirror speed and image position are accomplished simultaneously, firing the detonator.

The streak image is recorded on Kodak TRI-X pan film along with static photographs of the test shot and slit overlay (Fig. 9). The film is developed in Kodak D19 developer (full strength) at $21 \mathrm{C}$ for 12 minutes, then forwarded to the analyst after stop and fix baths.
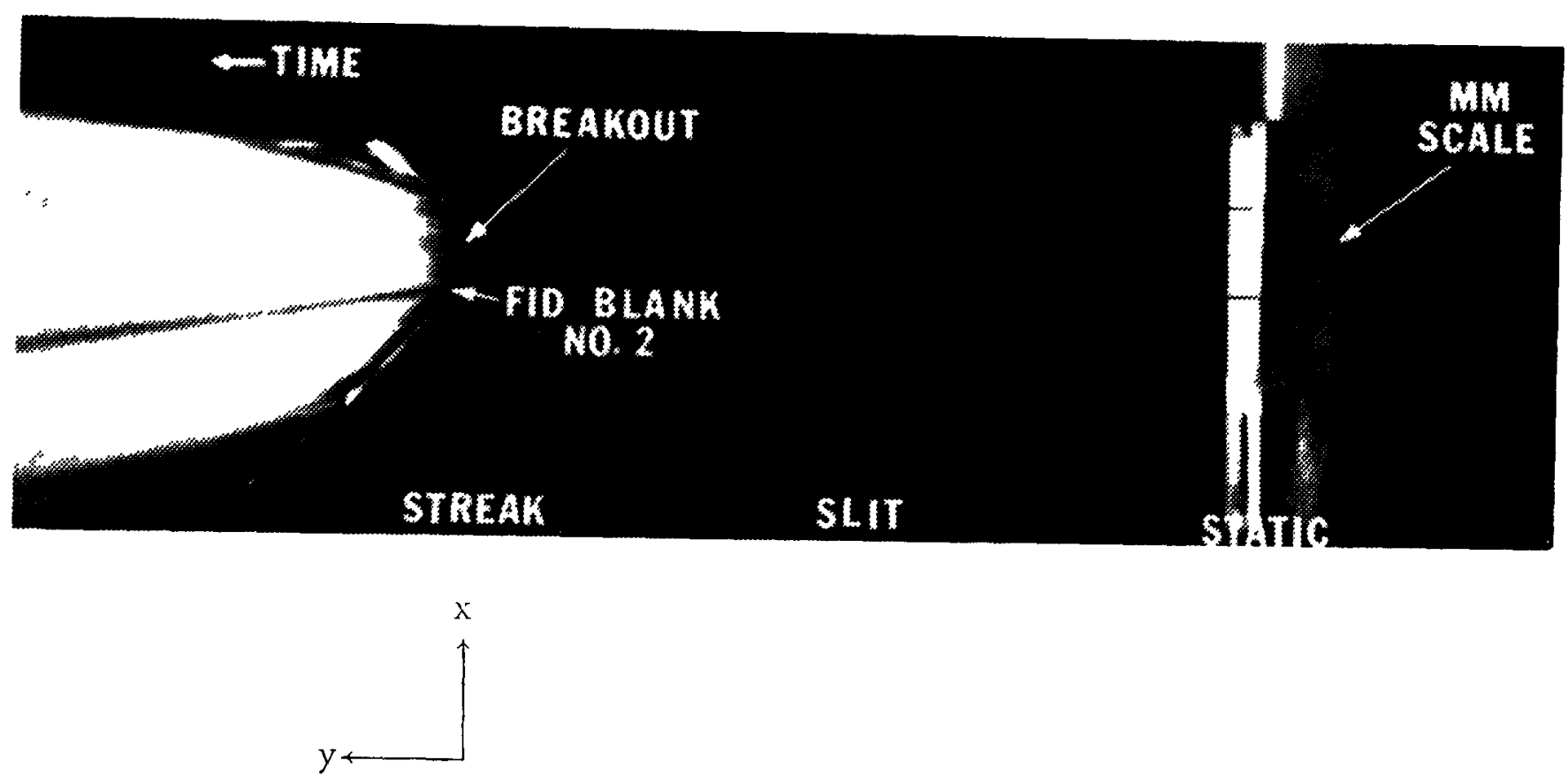

Fig. 9. Corner Turning Streak Record 


\section{DATA REDUCTION}

Film records are analyzed on an 0scar$S$ film reader at approximately 18:1 magnification. A precision scale is measured from the static photograph to calculate the camera/Oscar magnification.

Mag. $=2.54\left(\frac{x \text { Counts for } 1.0 \mathrm{~cm}}{1000}\right)$

Streak camera writing rate is calculated from the writing arm length and the rotating mirror camera (RMC) period.

$$
W R=\frac{4000}{\text { RMC Period }}
$$

The writing rate is calculated to verify consistence in curvature of streak records and is not used in data processing. It is held to within $0.2 \%$ from a nominal $10 \mathrm{~mm} / \mu \mathrm{s}$.

Fiducial wire separation distance is measured from the static photograph and compared for agreement of $0.07 \mathrm{~mm}$ to the corresponding cathetometer measurement. Disagreement will indicate errors in the reader magnification and/or cathetometer. During part build-up, a similar comparison is performed for cathetometer agreement to a precision height gage.

A digitized curve of the streak profile is obtained with alignment referenced to the static slit line. The data field consists of approximately $125 \mathrm{X}-\mathrm{Y}$ coordinate readings. This field, approximately $8 \mathrm{~mm}$ wide on the $\mathrm{X}$-axis, is controlled for symmetry of the $\mathrm{Y}$-axis ranges. The two fiducial blanks are kept just out of the field to assure consistant data point intervals of approximately 0.06 to $0.07 \mathrm{~mm}$. Either of the two fiducial blanks serves as a reference for the data coordinate axis; however, due to the non-symmetry of the streak trace, the $\mathrm{X}$-axis must be zero near fiducial blank No. 2 .

These data are curve fitted by polynominal regression to a third degree equation.

$$
\mathrm{Y}=\mathrm{b}_{0}+\mathrm{b}_{1} \mathrm{X}+\mathrm{b}_{2} \mathrm{X}^{2}+\mathrm{b}_{3} \mathrm{X}^{3}
$$

Constants $b_{1}, b_{2}$, and $b_{3}$ are used to calculate the $\mathrm{X}$ coordinate of the detonation breakout position.

$$
x=\frac{-b_{2}+\left(b_{2}^{2}-3 b_{1} b_{3}\right)^{1 / 2}}{3 b_{3}}
$$

The fiducial blank No. 2 center line coordinate is added to this and the sum is subtracted from the cathetometer measurement of the corner distance from fiducial wire No. 2 center line. The result is the distance from corner to breakout.

Finally, the standard error of estimate for $Y$ (SEOE) and standard errors of the regression coefficients are calculated to check reliability of the data. Table I lists some typical data obtained from a shot record on TRI-X film. The corresponding plot is shown in Fig. 10.

Table I. Typical Shot Data with TRI-X Film (Shot No. 22-10-10-2-78)

$X$ Coordinate of Breakout (mm)

Fiducial Blank 2 Coordinate (mm)

Coefficient
$b_{1}\left(m^{-1}\right)$
$-0.58878$
$\mathrm{b}_{3}\left(\mathrm{~mm}^{-2}\right)$
0.049115
0.001884

Standard Error ( $\left(\frac{0}{6}\right)$

$b_{1}$

$b_{2}$

0.8

2.5

4.8

Std. Error of Estimate for $Y(\mathrm{~mm})$

0.014

Corner to Fiducial Wire 2 (mm)

19.975

Corner Breakout (mm)

14.68

Magnification

17.766

Number of X-Y Data Points 126 


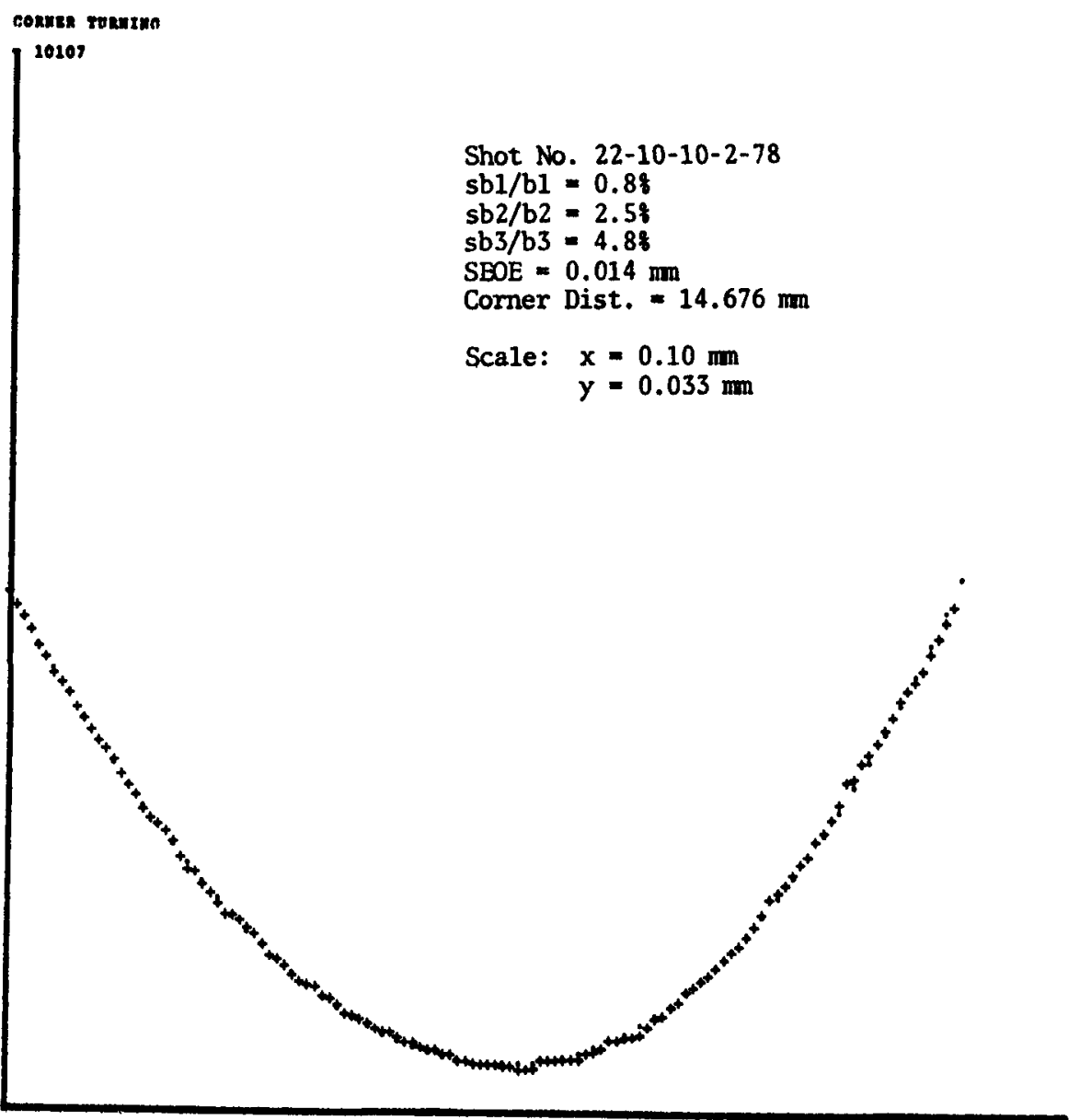

Fig. 10. Plot of Cubic Curve Fit (Cross Denotes Data Points and Dot Denotes Curve Fit)

Other curves were considered before selecting Equation 3 for analysis. Table II presents the F values, SEOE, and standard errors of regression coefficients of polynomial equations up to 8 degrees (each equation considered sequentially) for the example in Table I.

Table II. F Values and Standard Errors for $1^{\circ}$ to $8^{\circ}$ Equations

\begin{tabular}{|c|c|c|c|c|c|c|c|c|c|c|}
\hline Degree & $\underline{F \text { Value }}$ & $\begin{array}{l}\text { SEOE } \\
(\mathrm{mm})\end{array}$ & $\begin{array}{l}s b_{1} \\
(\xi)\end{array}$ & $\begin{array}{c}\mathbf{s b}_{2} \\
(\boldsymbol{l})^{2}\end{array}$ & $\begin{array}{c}\mathbf{s b}_{3} \\
(\boldsymbol{q}) \\
\end{array}$ & $\begin{array}{c}\mathbf{s b}_{4} \\
(\mathbf{8}) \\
\end{array}$ & $\begin{array}{r}\mathbf{s b}_{5} \\
(\boldsymbol{f})\end{array}$ & $\begin{array}{r}\mathrm{sb}_{6} \\
(\boldsymbol{g}) \\
\end{array}$ & $\begin{array}{c}s_{7} \\
(\mathbf{l})\end{array}$ & $\begin{array}{r}\mathbf{s b}_{8} \\
(\mathbf{g})\end{array}$ \\
\hline $\begin{array}{l}1 \\
2 \\
3 \\
4 \\
5 \\
6 \\
7 \\
8\end{array}$ & $\begin{array}{l}0.845 \\
11495 \\
44156 \\
35600 \\
47166 \\
49796 \\
42578 \\
38269\end{array}$ & $\begin{array}{l}0.454 \\
0.030 \\
0.014 \\
0.013 \\
0.010 \\
0.009 \\
0.009 \\
0.009\end{array}$ & $\begin{array}{r}109 \\
0.6 \\
0.8 \\
1.6 \\
1.8 \\
2.9 \\
4.4 \\
5.5\end{array}$ & $\begin{array}{r}0.6 \\
2.5 \\
11.2 \\
7.9 \\
77.5 \\
14.0 \\
60.0\end{array}$ & $\begin{array}{r}4.8 \\
17.0 \\
14.2 \\
32.5 \\
52.3 \\
95.9\end{array}$ & $\begin{array}{l}30.6 \\
11.7 \\
25.7 \\
55.7 \\
72.2\end{array}$ & $\begin{array}{l}10.2 \\
20.4 \\
63.1 \\
60.4\end{array}$ & $\begin{array}{l}16.7 \\
79.6 \\
53.7\end{array}$ & $\begin{array}{c}100 \\
50.8\end{array}$ & 33.3 \\
\hline
\end{tabular}


The second degree appears to be a reasonable fit, but inspection of plots reveal a biased shift (approximately $+0.15 \mathrm{~mm}$ ) of the breakout point (using a $9 \mathrm{~mm}$ data field) due to nonsymmetry of data (see Fig. 11). The higher degree equations produce small residuals, but the dependence of breakout point to coefficients prohibit accurate calculations for equations higher than three degrees. The $F$ values are all adequate with exception of the linear equation. The cubic equation was chosen over other polynomials as well as logarithmic curves, exponential curves, etc.

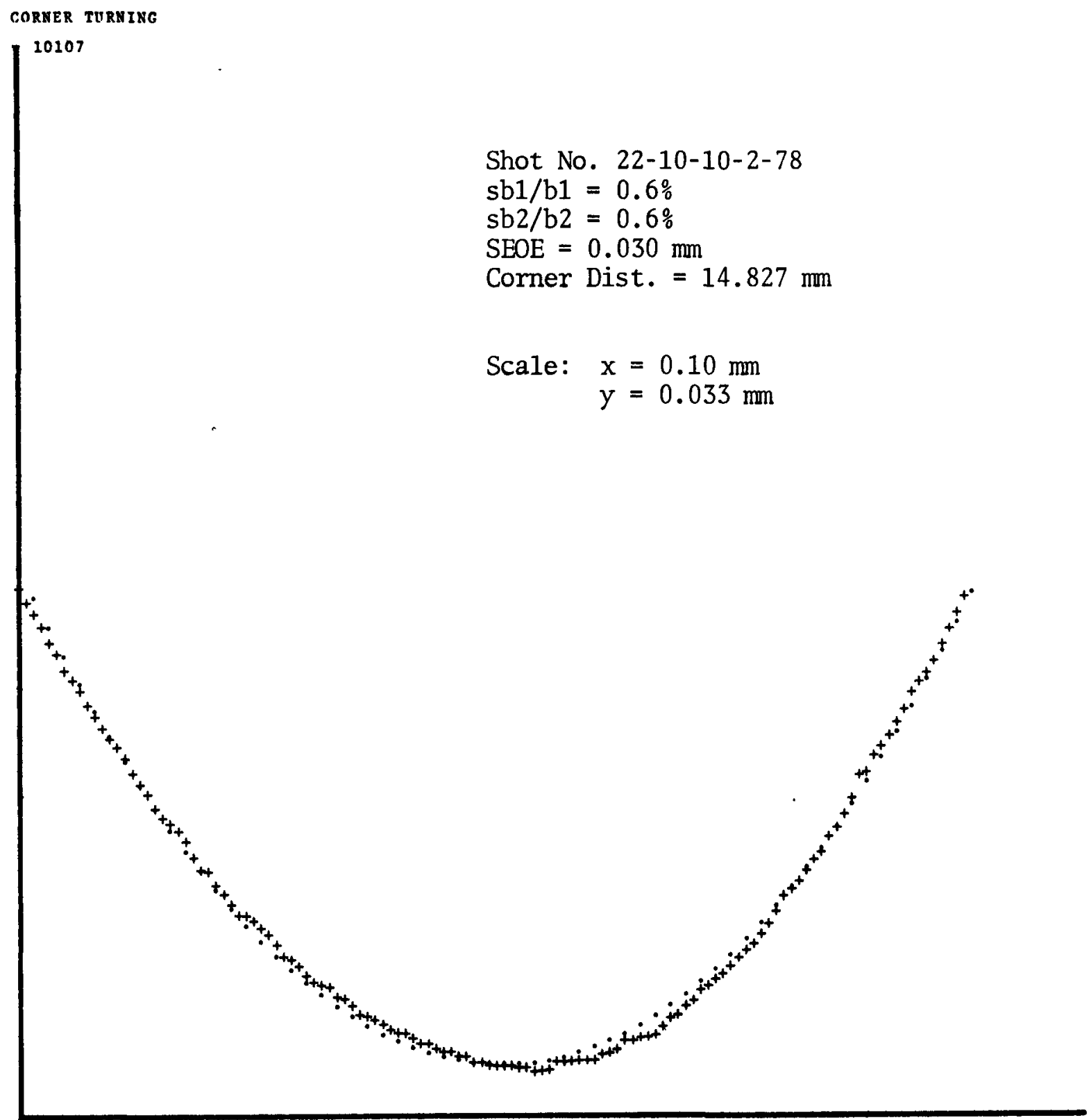

Fig. 11. Plot of Quadratic Curve Fit (Cross Denotes Data Points and Dot Denotes Curve Fit) 
Table III lists the corner to breakout distance for six shots fired during technique development. Test charge density is included; however, these tests were performed for testing development, and were not selected for variation in density. The expected lot-to-1ot variation of $\pm 2.1 \mathrm{~mm}$ is estimated from these shots and similar tests performed by LASL.

Table III. Corner Turning Distances of Six Shots

\begin{tabular}{|c|c|c|}
\hline Shot No. & $\begin{array}{l}\text { PBX } 9502 \\
\text { Density } \\
\left(\mathrm{g} / \mathrm{cm}^{3}\right) \\
\end{array}$ & $\begin{array}{c}\text { Breakout } \\
\text { Distance } \\
\text { (mm) }\end{array}$ \\
\hline $\begin{array}{l}22-7-7-2-78 \\
22-7-19-1-78 \\
22-10-2-1-78 \\
22-10-3-1-78 \\
22-10-10-2-78 \\
22-10-11-1-78\end{array}$ & $\begin{array}{l}1.8991 \\
1.8992 \\
1.8930 \\
1.8924 \\
1.8927 \\
1.8929\end{array}$ & $\begin{array}{l}15.69 \\
16.65 \\
16.04 \\
15.77 \\
14.68 \\
15.87\end{array}$ \\
\hline $\begin{array}{l}\text { Mean } \\
\text { Std. Dev. }\end{array}$ & . & $\begin{array}{r}15.8 \\
0.6\end{array}$ \\
\hline
\end{tabular}

\section{ERROR ANALYSIS}

Four of the corner turning tests were recorded on Kodak 2479 RAR film. One of these films was pushed one stop in the developer in an attempt to increase optical density on the streak. This resulted only in an increase of "fog," or background density. Fiducial blanks were difficult to read on the $2479 \mathrm{film}$ tests and consequently required a reduction in reader magnification. The standard deviation for reading the fiducial blank coordinate is $0.03 \mathrm{~mm}$ (sample size 30) on 2479 film at $12: 1$ reader magnification. One of these records was read seven times without changing the magnification or fiducial blank coordinate. The resulting standard deviation of the breakout (Equation 4) is 0.043 $\mathrm{mm}$ and the estimated true standard deviation is $0.046 \mathrm{~mm}$.
After Kodak TRI-X pan film was acquired, two additional corner turning tests were fired. Optical density, on the film, increased considerably and the streak record produced improved definition. Reader magnification was increased to 18:1 and reading tests were repeated as described above. The standard deviation for reading a fidicual blank on TRI-X film is 0.004 $\mathrm{mm}$, and the standard deviation $(\mathrm{n}=7)$ of the breakout (Equation 4) is 0.01 $\mathrm{mm}$.

This standard deviation $(0.01 \mathrm{~mm})$ represents the repeatability of reading and curve fitting the particular streak record itemized in Table $I$. This should be representative of other records with equivalent curvature and statistical quality, i.e., SEOE and standard errors of coefficients.

The data from one reading, on TRI-X film, are presented in Table I. The SEOE and standard errors of coefficients agree with the mean values for all of the seven readings. The estimated ranges of the SEOE and coefficient errors are listed in Table IV. These are slightly larger than maximum values from shots recorded on TRI-X film.

Table IV. Expected Maximum Values for Curves

$\begin{array}{lll}\mathrm{SEOE} & =0.015 \mathrm{~mm} \\ \mathrm{sb}_{1} / \mathrm{b}_{1} & =0.9 \% \\ \mathrm{sb}_{2} / \mathrm{b}_{2} & =2.7 \% \\ \mathrm{sb}_{3} / \mathrm{b}_{3} & =5.3 \%\end{array}$

The six corner turning tests reveal only slight variations of streak curvatures whose effects on the variant of SEOE and coefficient errors are immeasurable. Writing rate variant is maintained to $\pm 0.2 \%$ for consistency of curvature. If greater deviations occur, special consideration will be given to determine any effects. During the six tests, calculated writing rates varied only $0.08 \%$ from $10 \mathrm{~mm} / \mu \mathrm{s}$. 
Although the repeatability standard deviation $(0.01 \mathrm{~mm})$ adequately describes reading ability, the standard errors of regression coefficients represent the reliability of the breakout point from Equation 4 . Effects of the regression errors on Equation 4 are estimated by a MonteCarlo program. Basically, the MonteCarlo technique involves defining the individual errors associated with the parameters in Equation 4. Once the magnitude and probability distribution have been assigned for each error, the Monte-Carlo program operates on Equation 4 with the assigned errors. The program computes a single value for the measurement system using component values randomly selected from the assigned component distributions. This is a repetitive procedure and a total of 2000 points are generated for a measurement system. A histogram is plotted and a standard deviation is obtained for 2000 points. The frequency distribution indicates

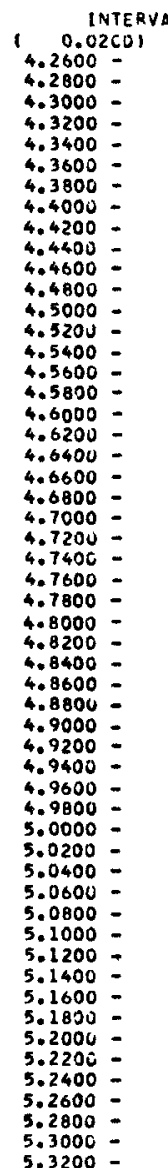

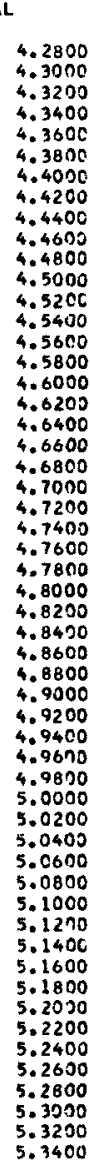

FREQ

Fig. 12 expected behavior of Equation 4 due solely to the assigned errors.

Equation 4 is expressed for error analysis as:

$$
\begin{aligned}
\mathrm{Q}(1)= & (-\mathrm{X}(2)+\operatorname{SQRT}((\mathrm{X}(2) * * 2) \\
\left.\left.-\left(3^{*} \mathrm{X}(1) * X(3)\right)\right)\right) /\left(3^{*}\right. & \\
\mathrm{X}(3)) . & \\
\mathrm{X}(1)= & -0.58878 \\
\sigma & =0.0053 \\
\mathrm{X}(2) & =0.049115 / \mathrm{mm} \\
\sigma & =0.00133 / \mathrm{mm} \\
\mathrm{X}(3) & =0.001884 / \mathrm{mm}^{2} \\
\sigma & =0.00010 / \mathrm{mm}^{2}
\end{aligned}
$$

where

These regression coefficients are taken from Table $I$ and their errors are assigned from Table IV. The Monte-Carlo histogram for $\mathrm{Q}(1)$ is presented in Fig. 12 and the corresponding statistical data are tabulated in Table V. Note that B Sub2 
Table V. Monte-Carlo Statistics for Cubic Curve Fit Errors

(Sample Size - 2000)

$\begin{array}{ll}\text { Mean } & 4.70109 \\ \text { Standard Deviation } & 0.09695 \\ \text { Range } & 0.68635 \\ \text { Variance } & 0.00940 \\ \text { Maximm X } & 5.05239 \\ \text { Maximm Possible X } & 5.05239 \\ \text { Upper 3 Sigma Limit } & 4.99196 \\ \text { Minimm X } & 4.36603 \\ \text { Minimm Possible X } & 4.36603 \\ \text { Lower 3 Sigma Limit } & 4.41023 \\ \text { Most Likely Value } & 4.71484 \\ \text { Mode } & 4.73000 \\ \text { Median } & 4.71000 \\ & \\ \text { Sum. X } & 0.94021897 \mathrm{D} \mathrm{04} \\ \text { Sum. X Square } & 0.44219376 \mathrm{D} \mathrm{05} \\ \text { Correction Term } & 0.44200586 \mathrm{D} 05 \\ \text { Sum. Small X Square } & 0.18790702 \mathrm{D} \mathrm{02} \\ \text { Std. Dev. (Mean) } & 0.21679542 \mathrm{D}-02 \\ \text { Variance (Mean) } & 0.47000255 \mathrm{D}-05 \\ & \\ \text { Normality Test } & \\ \text { Third Moment } & -0.20572592 \mathrm{D}-04 \\ \text { Forth Moment } & 0.26923831 \mathrm{D}-03 \\ \text { SQRT B Sub 1 } & -0.22590170 \mathrm{D}-01 \\ \text { B Sub 2 } & 0.30500773 \mathrm{D} 01\end{array}$

should be numerically near 3.0 for a normally distributed histogram. The Monte-Carlo standard deviation 10.097 $\mathrm{mm}$ ) is greater than the repeatability tests suggest. This is a consequence of the irregularities found on a streak signature and curve fitting errors of the mode1 (Equation 3). Inhomogeneities within the flasher paper produce sporadic exposure variations along the streak record. These are reduced by selection of flasher papers, but are not totally eliminated.

The uncertainty of a breakout distance results from accumulated errors of the following:

1. Cubic curve fitting (just discussed).

2. Cathetometer measurement to fiducial wire.

3. Optical distortion of streak camera and film reader.
4. Locating the fiducial blank on a streak.

5. Determining the magnification from a static photograph.

6. Alignment of the test charge to slit.

Effects of these errors are simulated on the following Monte Carlo equation corresponding to the data in Table I.

$$
\begin{aligned}
Q(2)= & X(4)-\left(17.766^{*}(Q(1)\right. \\
& +X(5))) /(X(6) \\
& +X(7)) .
\end{aligned}
$$

where

$$
\begin{aligned}
& X(4)=19.975 \mathrm{~mm} \\
& \sigma=0.025 \mathrm{~mm} \\
& X(5)=0.583 \mathrm{~mm} \\
& \sigma=0.004 \mathrm{~mm} \\
& X(6)=17.766 \pm 0.3 \% \\
& \text { (rectangular pro- } \\
& \text { bability distri- } \\
& \text { bution) } \\
& X(7)=0.0 \\
& \sigma=0.02
\end{aligned}
$$

Equation 6 represents adding the fiducial blank center line coordinate $[X(5)]$ to Equation $4[Q(1)]$ and subtracting the results from the cathetometer measurement of corner distance from fiducial wire center line [X(4)]. Optical distortion errors are assigned to the magnification factor [X(6)] which is also affected by film reading errors $[X(7)]$ from the steel scale's image. Optical distortion is measured from a precision grid pattern which has been contact printed onto film, then calibrated at the Metrology Laboratory for actual coordinate dimensions at nominal $20 \mathrm{C}$. Cathetometer errors are determined by repeated measurements of calibrated steel gage blocks, assembled to simulate measurements from corner to fiducial wire center. The histogram and statistical data from Equation 6 are presented in Fig. 13 and Table VI, 
respectively. Note that additional system errors have little accumulative affect on the total system uncertainty.

Although curve fitting errors are most significant, direct reading of the breakout point is not considered reliable because of the large radius of curvature. Difficulty is also encountered when irregularities occur along this curvature. A reduced data field $(4 \mathrm{~mm})$ can be fitted to a quadratic equation, decreasing the non-symmetry effects, but both regression coefficient errors increase to $1.8 \%$ (60 data points). The resulting Monte Carlo standard deviations are $0.12 \mathrm{~mm}$ (curve fit) and $0.12 \mathrm{~mm}$ (breakout distance).
Table VI. Monte-Carlo Statistics for Corner Distance per Cubic Curve Fit

(Sample Size - 2000)

$\begin{array}{lc}\text { Mean } & 14.69217 \\ \text { Standard Deviation } & 0.10070 \\ \text { Range } & 0.64852 \\ \text { Variance } & 0.01014 \\ \text { Maximum X } & 14.99598 \\ \text { Maximm Possible X } & 15.37470 \\ \text { Upper 3 Sigma Limit } & 14.99428 \\ \text { Minimm X } & 14.34746 \\ \text { Minimm Possible X } & 13.80981 \\ \text { Lower 3 Sigma Limit } & 14.39007 \\ \text { Most Likely Value } & 14.67716 \\ \text { Mode } & 14.67000 \\ \text { Median } & 14.69000 \\ & \\ \text { Sum. X } & 0.29384350 \mathrm{D} 05 \\ \text { Sum. X Square } & 0.43174028 \mathrm{D} 06 \\ \text { Correction Term } & 0.43172001 \mathrm{D} 06 \\ \text { Sum. Smal1 X Square } & 0.20271240 \mathrm{D} 02 \\ \text { Std. Dev. Mean) } & 0.22517427 \mathrm{D}-02 \\ \text { Variance (Mean) } & 0.50703451 \mathrm{D}-05 \\ & \\ \text { Normality Test } & \\ \text { Third Moment } & 0.17634949 \mathrm{D}-04 \\ \text { Forth Moment } & 0.30298936 \mathrm{D}-03 \\ \text { SQRT B Sub 1 } & 0.17282189 \mathrm{D}-01 \\ \text { B Sub 2 } & 0.29493529 \mathrm{D} 01\end{array}$

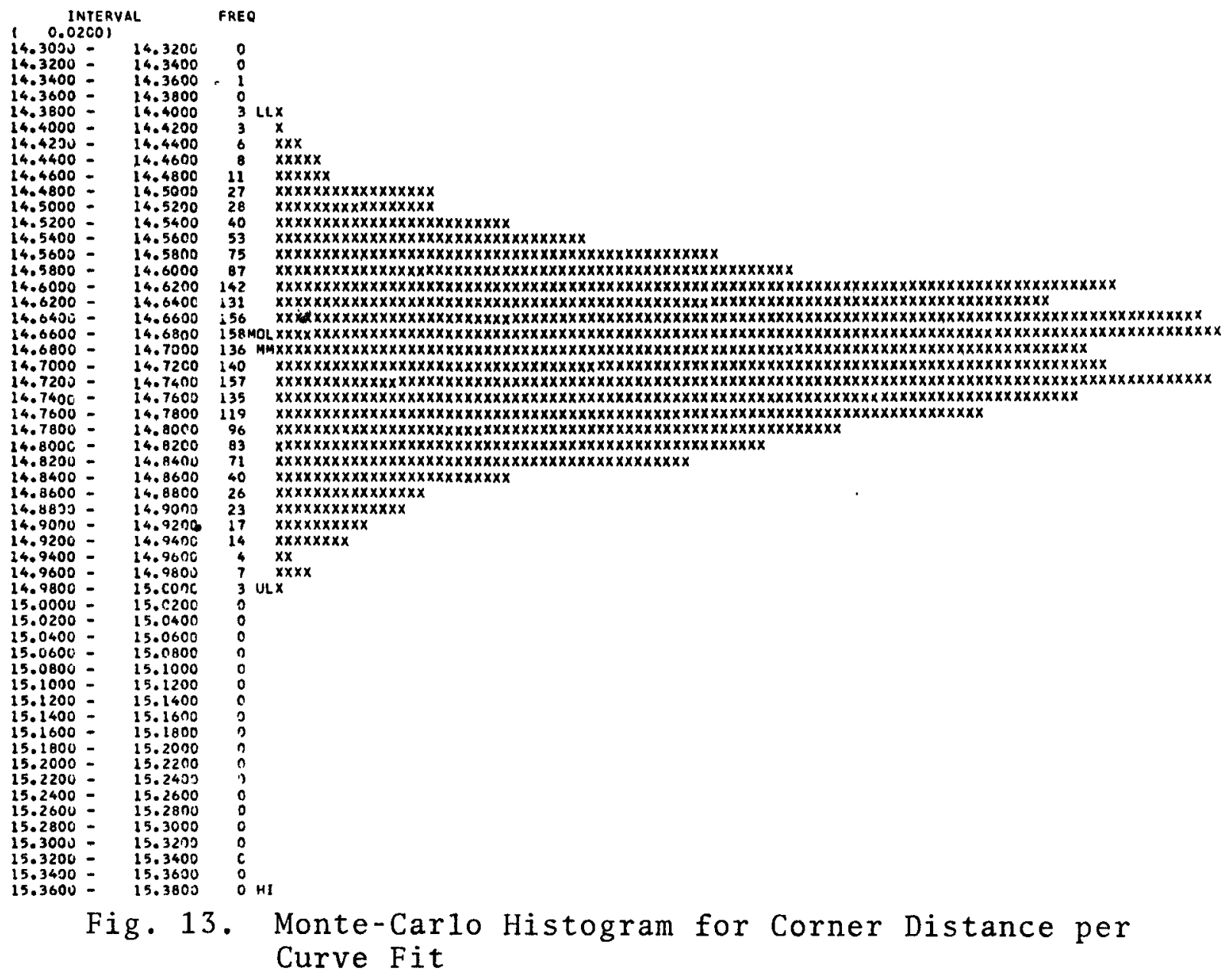


The incremental coordinate points $(0.06 \mathrm{~mm})$ are chosen to be compatible to image resolution (16 line pairs per $\mathrm{mm}$ ) as seen on a streak record via the film reader. As an estimate of the effects of streak irregularities, the film record corresponding to Table I was hand traced (with a french curve template) from the magnified image. The smooth curve trace was read seven times without changing in the fiducial blank coordinate. Reading repeatability standard deviation (cubic curve fit) is $0.003 \mathrm{~mm}$ for the breakout point.
Fig. 14 shows the results of one reading which is representative of the mean values for corner distance, SEOE, and regression coefficient errors. The same data set, fit to a quadratic, is presented in Fig. 15. A reduced field (same data), fit to a quadratic, is shown in Fig. 16. It appears that an ideal flasher (i.e., uniform illumination along a siit) could reduce corner distance errors by approximately one half for cubic curve fitting. A1so (in this case) a reduced field fit to a quadratic equation is promising.

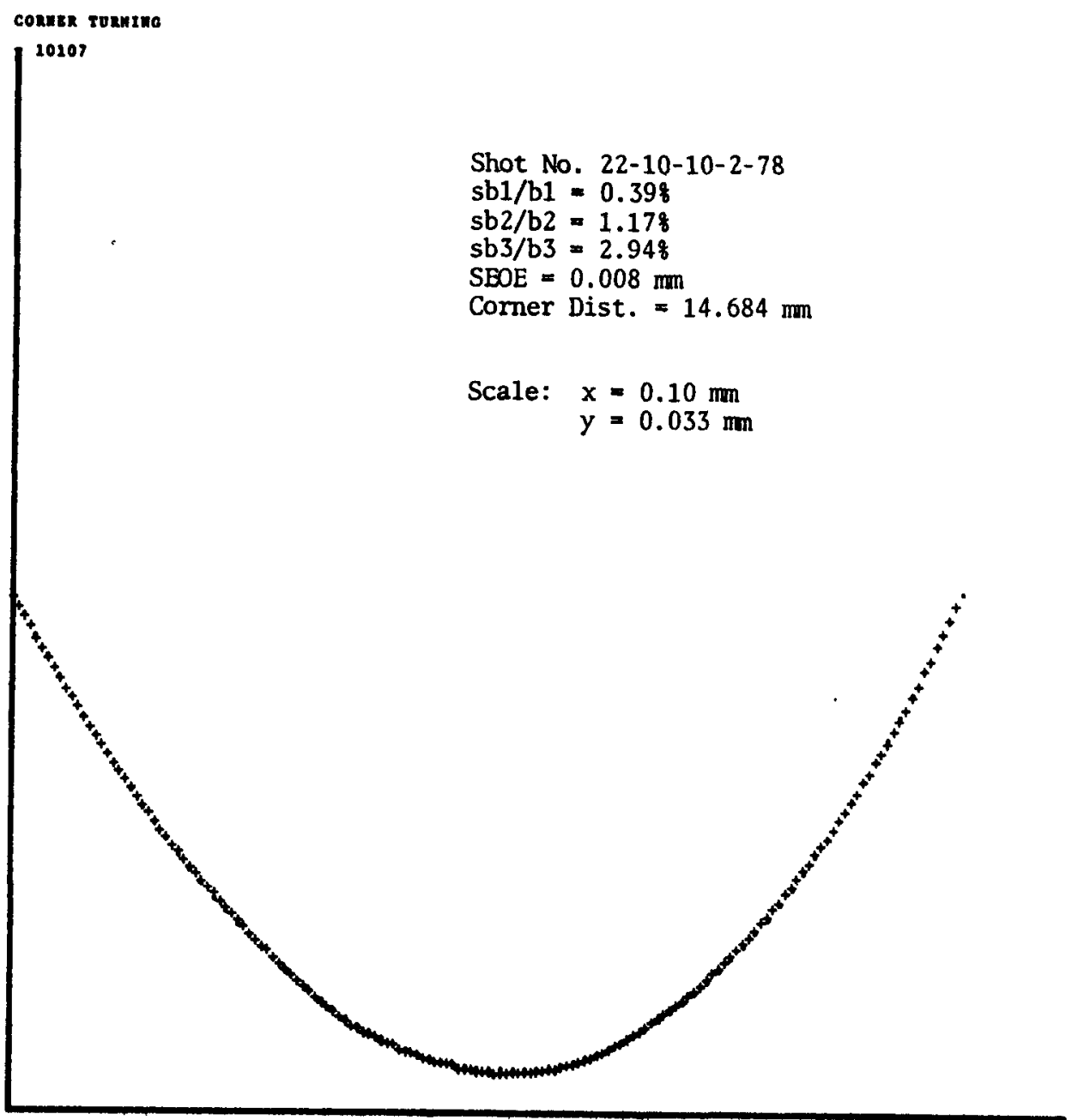

Fig. 14. Cubic Curve Fit to a Smooth Traced

Streak Record (Cross Denotes Data Points and Dot Denotes Curve Fit) 

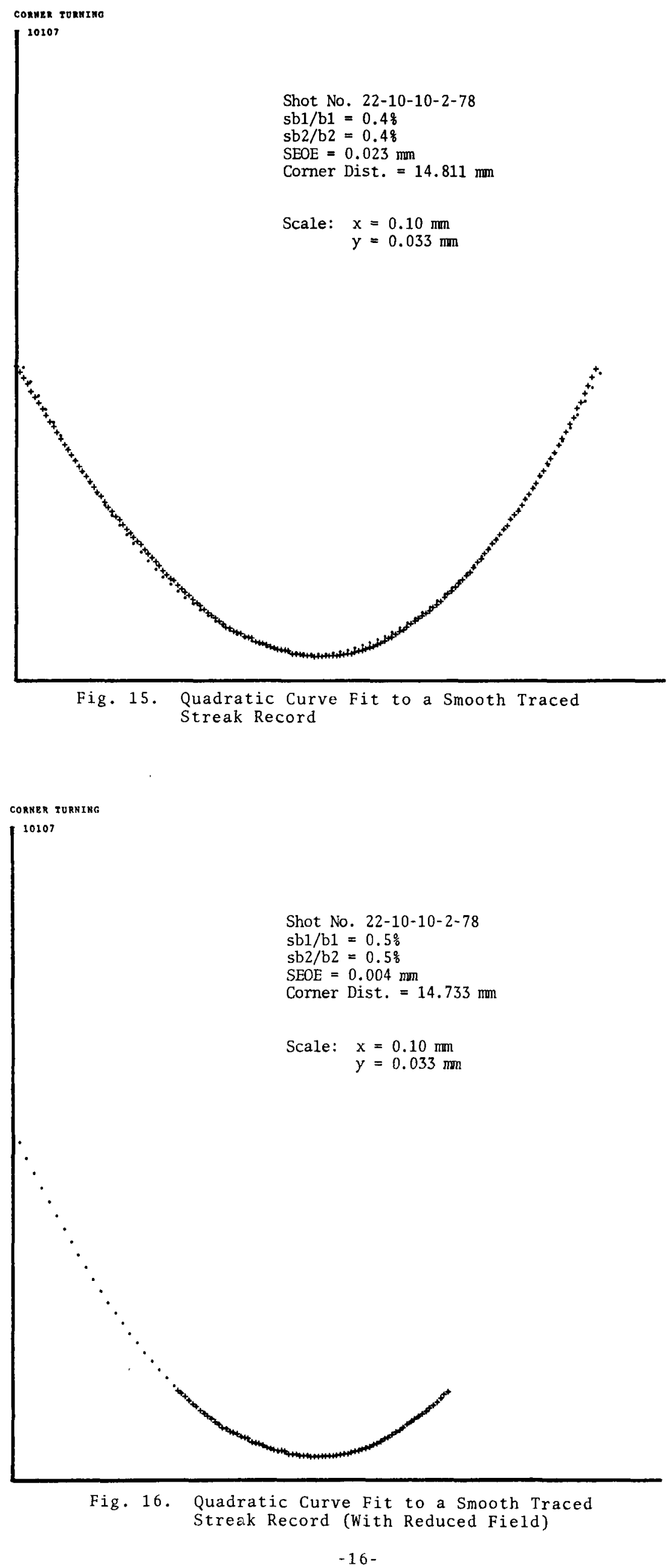


\section{CONCLUSIONS AND RECOMMENDATIONS}

Variation of corner turning breakout distance is expected to be approximately $\pm 2.1 \mathrm{~mm}$ as determined from previous tests. The expected mean breakout distance will be estimated pending more tests on lot-to-1ot samples from production fabricated explosives. PBX 9502 density is expected to affect corner turning properties, and some experimental testing on density and temperature effects should provide useful information for quality control.

A three degree polynomial regression equation is selected as the best model for curve fitting data in corner turning tests. Data fields (X-axis) of approximately $8 \mathrm{~mm}$ enclosing about 100 data points each are used to determine breakout distances. The uncertainty of a given corner turning test is estimated to be $\pm 0.2 \mathrm{~mm}$. This represents the 95\% prediction limits from Table VI. Kodak TRI-X pan film is required for corner turning tests, and extended development time is necessary to obtain high quality streak records.

\section{ACKNOULEDGEMENT}

The author wishes to express appreciation to J. K. Boettner, T. W. Warren, and Cathie Harris for their instructive discussions and encouragement during development and analysis of the test fire technique. The technique originated from LASL guidance via J. K. Boettner.

Temperature control studies on PBX 9502 were performed by L. L. Wooten and G. D. Rohrs. Mr. Rohrs also provided competent technical support during test fire of the corner turning tests.

The author is indebted to J. E. Metcalf for assembling the tests, to $\mathrm{J}$. K. Moore for analysis of the data, and to R. L. Shuttleworth for devising curve fitting programs used to compute and plot data.

Finally, the author wishes to thank Betty Reagh, Lou Garrett, Irene Luna and $\mathrm{H}$. E. Lowe for preparing the text, illustrations, and photographs of this report. 
$\underline{\text { DOE }}$

Ralph E. Caudle

Assistant Director of Operations

Military Application

Attn: Robert E. Clough

Washington, DC

$\underline{A L O}$

H. N. Meyer, Director

Weapons Development Division

R. R. Fredlund, Jr., Director

Classification \& Technical Information

AAO

P. M. Ramey, Chief

Operations Branch

Mound Facility

R. T. Braun .

SLL

R. D. Cozine - Org. 8180

$\underline{L L L}$

G. L. Dittman (10 Copies)

Attn: A. C. Van Dyk

C. T. Brockett, Technical

Information Dept.

LASL

E. H. Eyster - WX-DO

Attn: J. J. Wechsler

R. N. Rogers - WX-2

J. Aragon - WX-3

Report Library - ISD-4 $\underline{\text { SLA }}$

B. E. Arthur - Org. 1570

J. C. Crawford - Org. 2500/

D. H. Anderson - Org. 2510

J. C. King - Org. 2300/

C. B. McCampbe11 - Org. 2310

Central Technical Files - Org. 3141

TIC

Technical Information Center (27 Copies)

Oak Ridge, TN

$\underline{\text { PX }}$

Division Manager, Mfg. Engineering

Division Manager, Quality

Division Manager, Development

Division Manager, Manufacturing

Division Manager, Safety \& Fire

Protection

Education \& Training Center (5 Copies)

Technical Library (5 Copies)

Circulation Copy:

(1) Asst. Plant Manager

(2) Plant Manager

(3) M\&HH-SM Co., Inc., Lexington, KY 